2011

\title{
Latino Parents' Motivations for Involvement in Their Children's Schooling: An Exploratory Study
}

Joan M. T. Walker

Christa L. Ice

Kathleen V.Hoover-Dempsey

Howard M. Sandler

Follow this and additional works at: https://researchrepository.wvu.edu/faculty_publications

\section{Digital Commons Citation}

Walker, Joan M. T.; Ice, Christa L.; Hoover-Dempsey, Kathleen V.; and Sandler, Howard M., "Latino Parents' Motivations for Involvement in Their Children's Schooling: An Exploratory Study" (2011). Faculty Scholarship. 213.

https://researchrepository.wvu.edu/faculty_publications/213 


\title{
'LATINO PARENTS' MOTIVATIONS FOR INVOLVEMENT IN THEIR CHILDREN'S SCHOOLING
}

\author{
An Exploratory Study
}

\begin{abstract}
A B S T RA C T
This study examines the ability of a theoretical model of

the parental involvement process to predict Latino par-

ents' involvement in their children's schooling. A sample of Latino parents $(N=147)$ of grade 1 through 6 children in a large urban public school district in the southeastern United States responded to surveys assessing modelbased predictors of involvement (personal psychological beliefs, contextual motivators of involvement, perceived life-context variables), as well as levels of home- and school-based involvement. Home-based involvement was predicted by partnership-focused role construction (a personal psychological belief) and by specific invitations from the student (a contextual motivator of involvement). School-based involvement was predicted by specific invitations from the teacher (a contextual motivator) and by perceptions of time and energy for involvement (a life-context variable). Results are discussed with reference to research on Latino parents' involvement in children's schooling, as well as suggestions for school practices that may encourage parents' involvement.
\end{abstract}

Joan M. T. Walker PACE UNIVERSITY Christa L. Ice WEST VIRGINIA UNIVERSITY

Kathleen V. Hoover-Dempsey Howard M. Sandler VANDERBILT UNIVERSITY

THE ELEMENTARY SCHOOL JOURNAL VOLUME 111, NUMBER 3

(C) 2011 by The University of Chicago. All rights reserved. o013-5984/2011/11103-0003 $\$ 10.00$ 
A

C R O S S socioeconomic and demographic groups, parents' active involvement in children's schooling has been positively linked to a host of student outcomes including academic achievement and attitudes and skills that lead to achievement (Delgado-Gaitan, 2004; Fan \& Chen, 2001; Grolnick, Kurowski, Dunlap, \& Hevey, 2000; Jeynes, 2003, 2007). However, we have a limited understanding of why families become involved and their preferences for varied forms and levels of involvement, especially along cultural lines (Hill et al., 2004; Marschall, 2006; Rodriguez, 2009). Understanding this issue is important because it can inform educators' efforts to encourage the participation of a diverse array of families.

This study tested the ability of Hoover-Dempsey and Sandler's $(1995,1997,2005)$ model of the parental involvement process to explain Latino parents' involvement behaviors. Structured in sequential levels, the model identifies varied motivations for involvement (Level 1) and links them to a range of involvement forms (Level 1.5). Levels 1 and 1.5 are our focus. The upper levels of the model seek to explain how varied forms of involvement influence student outcomes. These levels examine parents' use of learning mechanisms during involvement (Level 2), students' perceptions of parents' activities (hypothesized to mediate the influence of involvement on student outcomes, Level 3), and their connection to student outcomes (student learning attributes and skills at Level 4; summary assessments of school learning and achievement at Level 5). ${ }^{1}$

Empirical work supports the model's predictive power concerning parents' motivations and involvement forms. In one study, for example, Level 1 constructs successfully explained significant portions of the variance in home-based $(39 \%)$ and school-based (49\%) involvement (Green, Walker, Hoover-Dempsey \& Sandler, 2007). Specifying forms of involvement is important because different types of parental involvement differentially influence student outcomes (Jeynes, 2003, 2007). Further, three consistent findings have emerged across tests of the model. First, many parents tend to be more involved in supporting their children's learning at home (e.g., helping with homework, discussing schoolwork and activities, affirming the value of education, or asserting positive expectations for the student's learning) than at school (e.g., attending parent-teacher conferences, visiting the classroom, volunteering, or helping with field trips; Anderson \& Minke, 2007; Deslandes \& Bertrand, 2005; Green et al., 2007). Differences in levels of home-based and school-based involvement are of practical importance because school personnel often define involvement in school-based terms, which may lead them to underestimate the time minority parents spend on less immediately visible home-based activities (Jackson \& Remillard, 2005).

Second, the most consistently robust predictors of parents' involvement are contextual motivators of involvement including parents' perceptions that their child and their child's teachers value and invite their participation (Anderson \& Minke, 2007; Deslandes \& Bertrand, 2005; Epstein \& Van Voorhis, 2001; Green et al., 2007; Hoover-Dempsey et al., 2005). Specific invitations to involvement from the teacher may include, for example, requests to review homework, requests to help with particular assignments, and personal requests to visit school or attend a school event (Balli, Demo, \& Wedman, 1998; Epstein \& Van Voorhis, 2001). Specific invitations to involvement from the student often include the student's direct requests for parental help as well as behavioral indicators that the parent's involvement is wanted or 
needed. These include, for example, the student's direct request for attendance at a school performance, parental help with school learning tasks, and the student's unspoken behavioral indicators of need for parental help (e.g., frustration, procrastination, struggles with a homework assignment); all have been found to influence parents' involvement behaviors (Balli et al., 1998; Delgado-Gaitan, 1992; HooverDempsey, Bassler, \& Burow, 1995).

Third and finally, parents' resources (i.e., time and energy, and knowledge and skills for involvement) are a relatively weak predictor of their involvement (Anderson \& Minke, 2007; Green et al., 2007). Taken together, these findings suggest that although parents often have limited resources, when they perceive that their child and their child's teachers want their involvement, "they find ways to be involved regardless of their resources” (Anderson \& Minke, 2007, p. 319).

With regard to the model's general applicability across cultures, the findings cited above reflect the responses of French Canadian secondary school parents (Deslandes \& Bertrand, 2005), African American and Latino elementary school parents in the United States (Anderson \& Minke, 2007), and Anglo-American, African American, and Latino parents of elementary and middle school students in the United States (Green et al., 2007). Our study explored more fully the model's ability to explain the home- and school-based involvement of a sample of Latino parents living in the United States.

\section{Latino Parents' Involvement}

Interest in Latino parents' involvement in their children's education in the United States has been spurred by reports of alarming differences in educational achievement between Latino students and students from other ethnic backgrounds (e.g., DeBlassie \& DeBlassie, 1996; Llagas \& Snyder, 2003). Several social and structural variables have been identified as contributors to this achievement gap including language barriers, limited parental education, poverty, discrimination, and residential instability (Bohon, Macpherson, \& Atiles, 2005; Delgado-Gaitan, 1994; Marschall, 2006). Other potential contributors are the often deficit-oriented character of many schools' perspectives on Latino families' involvement and related questions about the usefulness of active school efforts to support Latino parents' decisions to become involved (De Gaetano, 2007; Delgado-Gaitan, 2004; Reese, 2002; Valencia \& Black, 2002).

However, numerous studies suggest that despite these barriers, many Latino parents and families are actively involved in their children's education, and many Latino students are doing well in school (Delgado-Gaitan, 1992; Gillanders \& Jimenez, 2004; Reese, 2002; Rodriguez, 2002; Trevino, 2004; Waxman, Huang, \& Padrón, 1997). Consistent with this observation, recent examinations of Latino parents' involvement (including several ethnographic studies) have suggested that while most Latino parents value education, hold high educational aspirations for their children, and believe that supporting their children's education is very important (e.g., Garcia Coll et al., 2002; Gillanders \& Jimenez, 2004; Reese, 2002), the forms of involvement they choose may not be among those typically expected or observed by schools and teachers in many communities (Delgado-Gaitan, 1992; Scribner, Young, \& Pedroza, 1999; Trevino, 2004; Valdés, 1996). 
Examining the applicability of Hoover-Dempsey and Sandler's (2005) model of the parental involvement process to families whose children are at risk for academic underachievement is important because results might offer schools, communities, and families new perspectives and information regarding patterns of parents' engagement in their children's education and the factors that prompt their engagement. In the next section, we briefly describe the motivators of parental involvement included in Hoover-Dempsey and Sandler's model, linking each to literature supporting the importance of the construct in general and to Latino parents in particular.

\section{Motivators of Parental Involvement}

Hoover-Dempsey and Sandler's model identifies three major categories of parents' motivations for involvement: personal psychological beliefs, contextual motivators of involvement, and perceptions of life-context variables.

\section{Personal Psychological Beliefs}

Personal psychological motivators of involvement in the model include parental role construction for involvement (parents' beliefs about what they are supposed to do in relation to their children's schooling) and parents' sense of self-efficacy for helping their children succeed in school (parents' beliefs about whether or not their involvement is likely to positively influence their children's education).

Grounded in role theory (e.g., Biddle, 1986), parents' role construction for involvement assumes that parents develop ideas about what they are supposed to do (what role they are supposed to play) in their children's education, based on their own and important others' (e.g., family of origin, current and extended family members, friends) expectations. The construct has been examined as a continuous variable (i.e., stronger to weaker role activity beliefs; e.g., Chrispeels \& Rivero, 2001; Green et al., 2007; Sheldon, 2002) and as a categorical variable grounded in patterns of parental beliefs and behaviors (Hoover-Dempsey \& Jones, 1997). In the latter approach (used in this study), parents are examined for three patterns: parent-focused role construction (in which parents hold beliefs and manifest behaviors suggesting that they are primarily responsible for the student's school outcomes), partnershipfocused role construction (in which parents hold beliefs and engage in behaviors suggesting that they and the school share primary responsibility for the student's school outcomes), and school-focused role construction (in which parents believe and engage in behaviors suggesting that the school is primarily responsible for the student's school learning and outcomes).

Parental role construction has received considerable attention in the literature on Latino parents' involvement. Many accounts, for example, have suggested that while Latino parents often hold high expectations for their children's educational attainment, they also believe that it is the school's job to teach their children (Goldenberg, Gallimore, Reese, \& Garnier, 2002). This belief leads parents to avoid involving themselves in a teaching role related to school content because it demonstrates disrespect for teachers' roles, knowledge, and expertise (Reese, 2002; Reese, Balzano, Gallimore, \& Goldenberg, 1995). Even in this context, however, several investigators have noted that many Latino parents play home-based support roles in their chil- 
dren's education in a variety of ways, such as stating aspirations for the child's learning, emphasizing the value of education and the importance of respect for others, monitoring the child's schoolwork and peer relationships, and talking with the child about school (Delgado-Gaitan, 1992; Goldenberg et al., 2002; Reese, 2002; Trusty, Plata, \& Salazar, 2003).

Still other researchers have offered a view of Latino parents' involvement as more actively engaged with schools in supporting their children's educational success. Delgado-Gaitan (1992), for example, reported that parents of advanced first-grade readers (in contrast to parents of novice first-grade readers) took an active role in communicating with teachers, often asking for specific suggestions for helping their children (see also Drummond \& Stipek, 2004; Gillanders \& Jimenez, 2004; Okagaki, Frensch, \& Gordon, 1995). Trevino (2004) examined the Mexican migrant families of high-achieving secondary students in the southwestern United States and found that these parents considered themselves to be partners with their children's teachers and provided as much academic support, particularly at home, as they could. They also reported regular involvement in several school-based activities, including conferences regarding their children's academic performance, advocacy for their children's needs, and attendance at schoolwide meetings, especially when translation was routinely offered.

Taking a somewhat different approach to role construction and Latino parents, Chrispeels and Rivero (2001) reported on an adult "in-service" program for Latino immigrant parents focused on increasing the incidence and effectiveness of support for their students' learning. Intended to "bridge a cultural divide," the program emphasized building parents' beliefs about the importance of communicating with schools, actively supporting their students' learning, attending school events and meetings, and advocating for their students as needed. Participating parents recorded notable gains in each area and came to realize that they needed-and were expected-to play relatively active roles in supporting their students' learning in the United States. (For description of a similar program, see De Gaetano, 2007.)

Parental self-efficacy for involvement has also been noted in this literature. Grounded in Bandura's (1997) social cognitive theory, the construct includes parents' beliefs that their involvement activities will make a positive difference in their students' school learning. A stronger sense of efficacy for involvement has generally been associated with increased parental involvement behaviors, while a weaker sense of self-efficacy has been linked to lower levels of involvement (Hoover-Dempsey, Bassler, \& Brissie, 1992; Hoover-Dempsey et al., 2005).

Investigators of Latino families' involvement have noted the importance of selfefficacy in shaping parents' ideas and behaviors regarding involvement. Okagaki et al. (1995) reported, for example, that Mexican American families believed there were many things they could do to help their children succeed in school in the United States; these self-efficacy beliefs, however, were more positive for parents whose children were achieving well than for those whose children were doing more poorly. Garcia Coll et al. (2002) examined a construct similar to self-efficacy (the "proactive control [parents] believe they have over their child's educational path"; p. 311) and reported that among three immigrant groups (Dominican, Portuguese, and Cambodian) whose children were in public schools in the northeastern United States, Dominican parents held the most positive beliefs about parental control over student outcomes - a finding the researchers attributed to notable outreach efforts toward those parents in their children's schools. 


\section{Contextual Motivators of Involvement}

Consistent with Garcia Coll et al.'s (2002) findings that schools which made relatively strong efforts to reach out to parents (e.g., sending home information in Spanish, holding bilingual events at school, and providing Spanish-English bilingual education within the school) had more involved families, Hoover-Dempsey and Sandler's (2005) model suggests next that major contextual motivators of involvement include general invitations from the school, specific invitations to involvement from teachers, and specific invitations to involvement from the student. General invitations from the school include parents' perceptions of being welcomed at school by positive, encouraging, and responsive school members (Griffith, 2001). As reflected in the attitudes and behaviors of school staff, school environment may support increased parental involvement by helping parents feel they are valued members of the community and valued participants in their children's education (HooverDempsey \& Sandler, 1997, 2005; Walker, Wilkins, Dallaire, Sandler, \& HooverDempsey, 2005). Lopez, Sanchez, and Hamilton (2000) reported that parents of Hispanic elementary, middle, and high school students responded positively to consistent, empowering, and welcoming general school invitations for involvement.

Specific invitations from teachers have also been identified as a particularly powerful motivator of parents' active engagement in supporting their students' learning, at home and at school (Deslandes \& Bertrand, 2005; Epstein, 1986; Epstein \& Van Voorhis, 2001; Green et al., 2007; Simon, 2004). As a motivator of parents' homebased involvement, the construct is grounded in empirical work underscoring many parents' wishes to know more about how to help their children learn and succeed in school (e.g., Hoover-Dempsey et al., 1995, 2005; Hoover-Dempsey, Ice, \& Whitaker, 2009). It is also grounded in research demonstrating the power of teacher efforts to provide parents with this type of information (Balli et al., 1998; Moll, Amanti, Neff, \& Gonzalez, 1992; Patrikakou \& Weissberg, 2000). Moll et al. (1992), for example, described ideas for teachers' active support of Latino parents' home-based involvement, notably by developing student learning assignments that draw on parents' "funds of knowledge" or families' culture and expertise (see also Gonzalez, Andrade, Civil, \& Moll, 2001). The power of specific teacher invitations to prompt schoolbased involvement is often grounded in positive, trusting relationships developed between teachers and families (e.g., Christenson, 2004; Hoover-Dempsey et al., 2009). Such teacher invitations have been linked to increased levels of parental involvement in school-based activities (De Gaetano, 2007; Grolnick, Price, Beiswenger, \& Sauck, 2007; Kohl, Lengua, \& McMahon, 2002; Simon, 2004).

Specific invitations to involvement from the student have also been identified as a powerful predictor of parents' involvement, especially for home-based activities (Balli et al., 1998; Epstein \& Van Voorhis, 2001; Green et al., 2007; Hoover-Dempsey et al., 2005; Xu \& Corno, 2003). Consistent with Baumrind's (1989, 1991) and Maccoby's research (1992) suggesting that parents are generally motivated to respond to their children's needs and to support their successful development in areas including school learning, Hoover-Dempsey et al. (1995) found that parents generally want to be effectively involved in supporting their children's learning and often attend to their children's characteristics, interests, habits, needs, and behaviors relevant to school learning and success. Thus, when children indicate behaviorally (e.g., in struggling with homework or procrastinating in getting a school project done) or 
verbally and explicitly that they are having trouble with school tasks (e.g., "I need help," "I just don't understand this," "I hate school!"), they in effect invite parents' involvement. Considerable research further suggests that parents-across cultures and developmental lines - tend to respond to these invitations from students with efforts to help, ask questions, offer suggestions, or seek further advice from teachers and knowledgeable others, including family and social network members (e.g., Balli et al., 1998; Delgado-Gaitan, 1992; Grolnick, Benjet, Kurowski, \& Apostoleris, 1997; Hoover-Dempsey et al., 1995, 2005; Walker et al., 2005).

\section{Perceived Life-Context Variables}

Finally, the model suggests that parents' levels and forms of involvement are influenced by their perceptions of the skills and knowledge they bring to involvement as well as the time and energy they believe they can give to involvement. In general, parents' ideas about their skills and knowledge influence their involvement decisions across students' elementary, middle, and secondary school years (Hoover-Dempsey et al., 2005). Although many parents find their skills and knowledge sufficient for supporting their children's relatively early school learning, many parents also experience their skills and knowledge as inadequate as their children move into the middle and secondary school years. This is one reason that parental involvement tends to decline as children advance through the grades (Eccles \& Harold, 1996; Grolnick et al., 1997; Simon, 2004).

This influence of parents' perceptions of their skills and knowledge has been observed in studies of Latino families, and it appears to be particularly salient when parents doubt the usefulness of their skills and knowledge for helping their children's school learning (Drummond \& Stipek, 2004; Garcia Coll et al., 2002). Similarly, parents' perceptions of the time and energy they can bring to involvement may present particular challenges for lower-income Latino families, as parents juggle job demands (or the demands of multiple jobs), extended family needs, and invitations or requests for involvement in their children's education (Garcia Coll et al., 2002; Pena, 2000; Weiss et al., 2003).

\section{Summary, Purpose, and Hypothesis}

This exploratory study applied Hoover-Dempsey and Sandler's (1995, 1997, 2005) model of the parental involvement process to a sample of Latino public school parents. Based on prior tests of model constructs across cultural and developmental lines (Anderson \& Minke, 2007; Deslandes \& Bertrand, 2005; Green et al., 2007), we hypothesized that the model's Level 1 constructs (personal psychological beliefs including role construction and self-efficacy for involvement; contextual motivators of involvement including invitations from school, teacher, and student; and perceived life-context variables including time and energy, and skills and knowledge for involvement) would account for a significant portion of the variance in Latino parents' reports of home-based and school-based involvement.

\section{Participants and Procedures}

Participants were drawn from a public school system in a large metropolitan area of the southeastern United States. The district was selected in part because the area had 
recently become home to a largely new and relatively fast-growing Latino population made up primarily of immigrants from Mexico. At the time of the 2000 U.S. Census, the city was second in overall population within the state and home to the largest portion of the state's Latino population. While the proportion of total residents in the city represented by these new Latino families was relatively small (4.7\%; the percentage of Latino residents in the entire state was then $2.2 \%$ ), the new Spanishspeaking families confronted the major task of accommodating and acculturating to an environment accustomed to a primarily bi-ethnic population (i.e., African American and Anglo-American). Although the system had seen the arrival of many different ethnic and nationality groups through the 1990s, the actual numbers in any of these groups were notably smaller than the rapidly growing number of Spanishspeaking families, most of whom (as noted in the demographic data below) spoke only Spanish or preferred Spanish to English.

The sample of Latino parents, almost all of whom were first-generation immigrants primarily from Mexico, was drawn from five schools in the system: three elementary schools (first through fourth grades) and two middle schools (fifth and sixth grades). All participants were part of a larger study in these five schools. Survey questionnaire packets were sent home with students in Spanish or English, depending on the school's information about parents' preferred or only language. In some circumstances, surveys were sent home in both languages so the parent could choose. Eighty-three percent of the 147 Latino parents identified Spanish as their only or primary language and responded to the Spanish forms (16\% responded to the surveys in English). The overall response rate from the schools for the full study (all ethnicities) was $37 \%(n=495)$. The 147 Latino parents examined in this study represented approximately $30 \%$ of this group.

Seventy-five percent of the responding Latino parents were female, and $61.4 \%$ reported being employed ( $21 \%$ reported employment of 39 hours or less per week, $29 \%$ reported 40 hours per week, and $12 \%$ reported more than 40 hours per week). Responses regarding level of education suggested that $52 \%$ had received less than a high school education, $26 \%$ had completed high school, $11 \%$ had completed some college, while another $11 \%$ had completed a college degree. Approximately $43 \%$ reported an annual family income of $\$ 10,000$ or less, $36 \%$ reported an annual income of $\$ 10,001-\$ 20,000,16 \%$ reported an annual income of $\$ 20,001-\$ 30,000$, and $5 \%$ reported an annual income over $\$ 30,000$.

\section{Measures}

Participants responded to questionnaires assessing the model's hypothesized predictors of parental involvement and parents' home- and school-based involvement. Developed during a 3-year, large-scale study, all measures underwent extensive piloting and face and construct validity assessments (see Hoover-Dempsey \& Sandler, 2005; Walker et al., 2005). ${ }^{2}$ Surveys were translated into Spanish by a native-Spanishspeaking translator who worked with the research team periodically to confirm the meaning of the constructs and wording of items. Examination of factor analysis (using maximum likelihood extraction and promax rotation) and internal consistency scores for data gathered during the larger study $(n=495)$ led to the trimming of several scales. The standardized alpha reliability figures and number of items per 
scale reported here represent the results of our refined measures. Measures of the predictor variables used a 6-point agree/disagree scale (strongly agree to strongly disagree). Parents' reports of home-based and school-based involvement used a 6-point never to daily response scale.

\section{Personal Psychological Beliefs}

Parental role construction. Role construction was assessed as a categorical variable. Parent-focused role construction, reflecting beliefs and behaviors suggesting that the parent believes that primary responsibility for the child's educational outcomes belongs to the parent, was measured with two items (sample item: "It's my job to make sure my child understands his/her assignments," $\alpha=.79$ ). Partnershipfocused role construction, reflecting beliefs and behaviors suggesting that primary responsibility for the child's school outcomes is shared between the parent and the school, was measured with four items (sample item: "I like to spend time at my child's school," $\alpha=.60$ ). School-focused role construction, reflecting beliefs and behaviors suggesting that primary responsibility for the child's education belongs to the teacher and school, was measured with three items (sample item: "My child's learning is mainly up to the school," $\alpha=.63$ ).

Self-efficacy for involvement. This four-item scale assessed parents' sense of their own capacity to be involved and the likely effectiveness of their involvement activities in helping the child learn and succeed in school (see Hoover-Dempsey et al., 1992; sample item: "I know how to help my child do well in school," $\alpha=.71$ ).

\section{Contextual Motivators of Involvement}

General school invitations. This six-item scale assessed parents' perceptions of being welcomed in the school as well as their perceptions of a positive, encouraging, and responsive school climate as conveyed by those working at the school (see Walker et al., 2005; sample item: "Teachers at this school are interested and cooperative when they discuss my child," $\alpha=.83$ ).

Specific teacher invitations. This four-item scale measured parents' perceptions of a variety of ways teachers may communicate a desire for the parents' involvement at school (sample item: "My child's teacher asked me to help out at the school," $\alpha=$ .76). Analysis of factor loadings and internal consistency scores led to the deletion of items asking parents about teacher invitations to involvement in home-based learning activities.

Specific student invitations. This two-item scale assessed parents' perceptions of student requests for help or engagement in home-based activities (sample item: "My child asked me to explain something about his or her homework," $\alpha=.74$ ). Analysis of factor loadings and internal consistency scores led to the deletion of items asking parents about student invitations to involvement in school-based activities.

\section{Perceived Life-Context Variables}

Time and energy for involvement. This four-item scale assessed parents' perceptions of demands on their time with regard to involvement in their child's education at home and at school (sample item: "I have enough time and energy to attend special events at school," $\alpha=.80$ ). 
Skills and knowledge for involvement. This four-item scale focused on parents' perceptions of the knowledge and skills they possess relevant to involvement in their child's education at home and at school (sample item: "I know how to explain things to my child about his or her homework," $\alpha=.81$ ).

\section{Outcome: Parental Involvement Forms}

Home-based involvement was measured with two items intended to capture common, academically focused home-based activities in which parents and children typically engage (e.g., "I helped my child with homework," $\alpha=.71$ ). School-based involvement was also measured with two items intended to capture common schoolbased activities in which public school parents might typically engage (e.g., "I helped out at my child's school," $\alpha=.76$ ).

\section{Results}

\section{Parents' Motivations for Involvement and Reported Levels of Involvement}

As noted by the descriptive statistics in Table 1, parents recorded varied but generally high levels of endorsement for the full set of motivators included in the model. Consistent with other reports (Anderson \& Minke, 2007; Deslandes \& Bertrand, 2005; Green et al., 2007), there was a notable difference in parents' home-based and school-based involvement. Parents were more involved at home $(M=5.30, S D=$ $.93)$ than at school $(M=2.85, S D=1.26 ; t(146)=22.31, p<.01)$. Higher scores on the 6-point scale indicate more involvement (e.g., $6=$ daily); lower scores indicate less involvement (e.g., $1=$ never).

\section{Relationships among Variables}

Zero-order correlations are presented in Table 1. We first examined correlations among the separate variables within each of the model's major predictor constructs (i.e., examined correlations among the variables comprising personal psychological beliefs, then relations among variables comprising the contextual motivators, etc.). We then looked at relations across variables within each major predictor construct. Finally, we examined relations between each variable and the two study outcomes.

Within the construct of personal psychological beliefs, all three categories of role construction were positively related (the parent-focused role was related to the partnership-focused role, $r=.28, p<.01$; the partnership-focused role was related to the school-focused role, $r=.26, p<.01$; the school-focused role was related to the parent-focused role, $r=.24, p<.01$ ). Only partnership-focused role construction was positively related to self-efficacy for involvement $(r=.22, p<.01)$. With regard to contextual motivators, all three sources of invitations (school, teacher, and student) were positively linked (general school invitations were related to specific teacher invitations, $r=.43, p<.01$; specific teacher invitations were related to specific student invitations, $r=.37, p<.01$; specific student invitations were related to general school invitations, $r=.25, p<.01)$. The two life-context variables, time and energy, and skills and knowledge for involvement, were also positively related $(r=$ $.51, p<.01)$. 


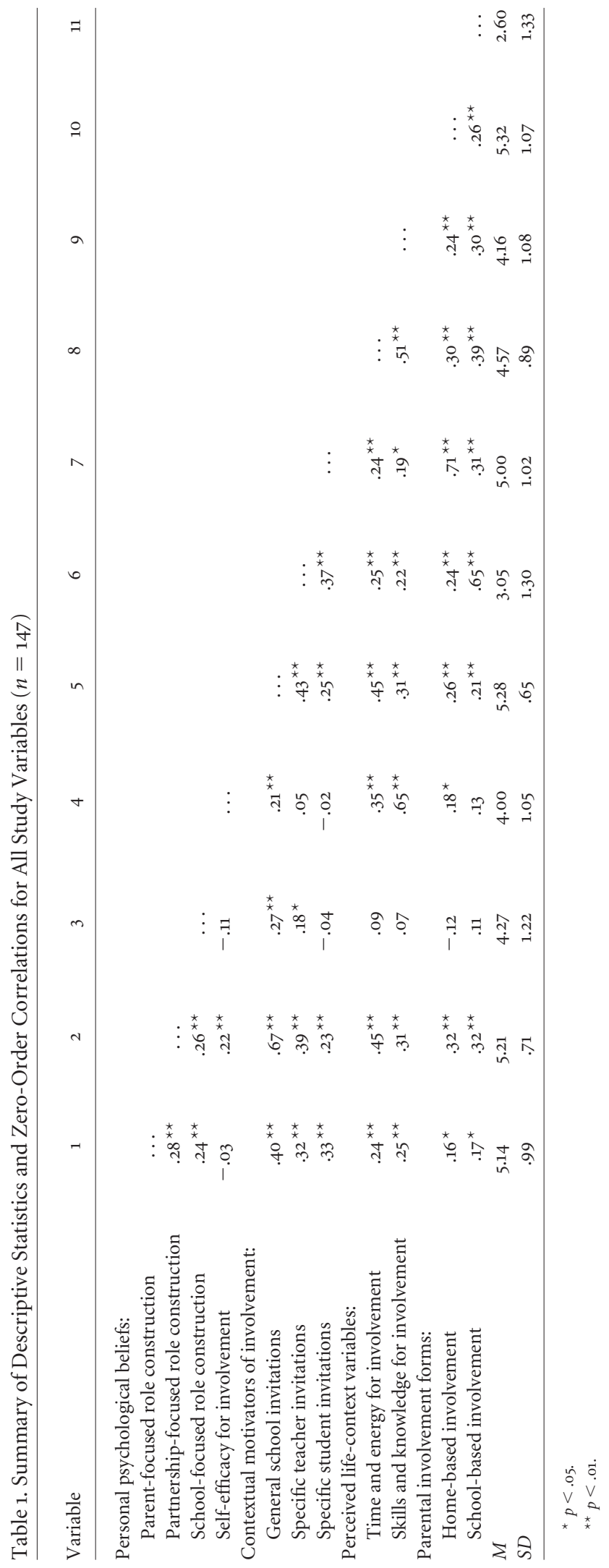

This content downloaded from 157.182.147.116 on October 05, 2018 10:23:45 AM 
Examination of correlations between individual variables across major constructs revealed two important findings. First, there was a positive correlation between general school invitations (a contextual variable) and endorsement of partnershipfocused role construction (a personal psychological motivator; $r=.67, p<.01$ ). Second, there was a positive correlation between parents' self-efficacy for involvement (a personal psychological motivator, often defined as parents' beliefs that their involvement will have an effective outcome or make a positive difference) and their perceived knowledge and skills for involvement (a life-context variable indicating parents' beliefs that they have the ability to make a difference; $r=.65, p<.01$ ).

Finally, the two parental involvement forms (home-based and school-based) were positively associated $(r=.26, p<.01)$. Further, home-based involvement was positively and significantly linked with each study variable with the exception of school-focused role construction. School-based involvement was positively and significantly associated with most study variables, the exceptions being school-focused role construction and self-efficacy for involvement.

\section{Predicting Involvement}

Hierarchical regressions were conducted using factors in the following blocks to predict parents' home-based and school-based involvement: Block 1 included personal psychological beliefs (partnership-focused, parent-focused, and schoolfocused role construction; self-efficacy for involvement); Block 2 included contextual motivators of involvement (general invitations from the school, specific invitations from the teacher, and specific invitations from the student); Block 3 included perceived life-context variables (time and energy and skills and knowledge for involvement). Results are reported in Table 2.

A significant portion of the variance in this group of Latino parents' reported homebased involvement was accounted for by model constructs, $F(9,146)=21.06, p<.01$, adj. $R^{2}=.55$. Block 1, personal psychological beliefs, predicted a significant portion of the variance $\left(\Delta R^{2}=.17, p<.005\right)$, as did Block 2, contextual motivators of involvement $\left(\Delta R^{2}=.41, p<.005\right)$; Block 3, perceived life-context variables, also contributed to the prediction, although not at a level reaching statistical significance $\left(\Delta R^{2}=.17, p<.69\right)$. Individual predictors of parents' home-based involvement that emerged as most important in the overall results included perceptions of specific invitations to involvement from the student $(\beta=.71)$ and partnership-focused role construction $(\beta=.19)$. Self-efficacy for involvement approached significance $(\beta=.14)$. The $R$-square values for the three blocks across order of entry into the equation (Block 1, Block 2, Block 3 ) do not sum to the total adjusted $R$-square (adj. $R^{2}=.55$ ), perhaps due to overlapping variance that occurred with the addition of Blocks 2 and 3 .

A significant portion of the variance in parents' reported school-based involvement, $F(9,146)=16.84, p<.005$, adj. $R^{2}=.49$, was also accounted for by model constructs. Block 1, personal psychological beliefs, predicted a significant portion of variance $\left(\Delta R^{2}=.10, p<.01\right)$; the addition of Block 2, contextual motivators of involvement, contributed another significant portion of variance $\left(\Delta R^{2}=.36, p<\right.$ .01); the addition of Block 3, perceived life-context variables, contributed an additional statistically significant portion of the variance $\left(\Delta R^{2}=.07, p<.01\right)$. Individual predictors of parents' school-based involvement included perceptions of specific teacher invitations $(\beta=.64)$ and perceptions of time and energy for involvement 
Table 2. Predictors of Latino Parents' Home- and School-Based Involvement $(n=147)$

\begin{tabular}{|c|c|c|c|c|c|c|}
\hline & \multicolumn{2}{|c|}{ Block 1} & \multicolumn{2}{|c|}{ Block 2} & \multicolumn{2}{|c|}{ Block 3} \\
\hline & $\beta$ & $p<$ & $\beta$ & $p<$ & $\beta$ & $p<$ \\
\hline \multicolumn{7}{|l|}{ Home-based involvement: } \\
\hline \multicolumn{7}{|l|}{ Personal psychological beliefs: } \\
\hline Partnership-focused role construction & .33 & .00 & .20 & .01 & .19 & .02 \\
\hline Parent-focused role construction & .13 & .11 & -.08 & .22 & -.08 & .25 \\
\hline School-focused role construction & -.23 & .01 & -.10 & .10 & -.10 & .12 \\
\hline Self-efficacy for involvement & .09 & .27 & .14 & .02 & .14 & .07 \\
\hline$\Delta R^{2}$ & .17 & .00 & & & & \\
\hline \multicolumn{7}{|l|}{ Contextual motivators of involvement: } \\
\hline General school invitations & & & .01 & .94 & -.01 & .94 \\
\hline Specific teacher invitations & & & -.07 & .30 & -.07 & .32 \\
\hline Specific student invitations & & & .71 & .00 & .71 & .00 \\
\hline$\Delta R^{2}$ & & & .41 & .00 & & \\
\hline \multicolumn{7}{|l|}{ Perceived life-context variables: } \\
\hline Time and energy for involvement & & & & & -.03 & .40 \\
\hline Skills and knowledge for involvement & & & & & .06 & .72 \\
\hline$\Delta R^{2}$ & & & & & .17 & .69 \\
\hline$F$ & & & & & 21.06 & .00 \\
\hline Adj. $R^{2}$ & & & & & .55 & \\
\hline \multicolumn{7}{|l|}{ School-based involvement: } \\
\hline \multicolumn{7}{|l|}{ Personal psychological beliefs: } \\
\hline Partnership-focused role construction & .26 & .01 & .13 & .12 & .07 & .41 \\
\hline Parent-focused role construction & .10 & .24 & -.03 & .71 & -.07 & .35 \\
\hline School-focused role construction & .03 & .74 & .03 & .62 & .03 & .68 \\
\hline Self-efficacy for involvement & .08 & .35 & .11 & .09 & -.02 & .78 \\
\hline$\Delta R^{2}$ & .10 & .01 & & & & \\
\hline \multicolumn{7}{|l|}{ Contextual motivators of involvement: } \\
\hline General school invitations & & & -.20 & .03 & -.25 & .01 \\
\hline Specific teacher invitations & & & .64 & .00 & .64 & .00 \\
\hline Specific student invitations & & & .11 & .12 & .07 & .33 \\
\hline$\Delta R^{2}$ & & & .36 & .00 & & \\
\hline \multicolumn{7}{|l|}{ Perceived life-context variables: } \\
\hline Time and energy for involvement & & & & & .28 & .00 \\
\hline Skills and knowledge for involvement & & & & & .09 & .30 \\
\hline$\Delta R^{2}$ & & & & & .07 & .00 \\
\hline$F$ & & & & & 16.84 & .00 \\
\hline Adj. $R^{2}$ & & & & & .49 & \\
\hline
\end{tabular}

$(\beta=.28)$. Parents' perceptions of general invitations from the school emerged as a negative predictor $(\beta=-.25)$, perhaps because another variable in the equation suppressed related variance. The individual block $\Delta R^{2}$ figures did not sum to the total adjusted $R$-square (adj. $R^{2}=.49$ ), perhaps due to overlapping variance with the addition of each new block.

\section{Discussion}

This study applied a theoretically and empirically grounded model of the parental involvement process to a sample of Latino parents of public elementary and middle school students. Its goal was to ascertain if motivational constructs included in the model could predict significant portions of the variance in parents' involvement at home and at school. Results for this sample of Latino parents suggested an affirma- 
tive answer as the model predicted $55 \%$ of the variance in their reported home-based involvement and $49 \%$ of the variance in their reports of school-based involvement.

Results contribute to current understanding of culturally related variations in families' varied forms and levels of involvement in children's education in three ways. First, insofar as the findings suggest that these parents were actively engaged in supporting their children's learning, especially at home, they contradict deficitoriented reports of Latino parents' involvement (see Valencia \& Black, 2002, for a review). Instead they align with reports of Latino parents' active engagement, including findings from some strong ethnographic studies (e.g., Delgado-Gaitan, 1992; Reese, 2002; Trevino, 2004) that have underscored the presence and influence of Latino parents' values, beliefs, and behaviors to their involvement in their children's school learning and educational success (see also De Gaetano, 2007; Garcia Coll et al., 2002).

Second, parents' greater involvement in home-based rather than school-based activities aligns with investigations of Latino and other parents' involvement (e.g., De Gaetano, 2007; Epstein, 1986; Trevino, 2004) and with prior quantitative tests of the model's ability to predict the involvement of minority families in the United States (Anderson \& Minke, 2007; Green et al., 2007). While this difference may simply reflect the reality that opportunities for home-based involvement may appear any day of the week across children's waking hours while opportunities for involvement at school are generally limited to hours and events made available by the school, it is important for two reasons. Empirically, research has documented the differential influence of different forms of parent involvement (Jeynes, 2003, 2007). Practically, it suggests that schools should be wary of assuming that parents who are not often present at school are not involved in supporting their children's learning. Many parents may provide more support for their children's schooling than school personnel perceive based on their visibility.

Third, these parents were motivated to participate in different forms of involvement (i.e., home-based and school-based) by different factors, a finding that underscores the importance of understanding why parents become involved. Consistent with prior tests of the model (Anderson \& Minke, 2007; Deslandes \& Bertrand, 2005; Green et al., 2007), contextual motivators (in this case, specific invitations from students and from teachers) played an important role in shaping parents' involvement behaviors, whereas personal psychological motivators and perceived lifecontext variables played a somewhat less important role.

\section{Predicting Home-Based Involvement}

Home-based involvement was predicted by two model constructs-one a contextual motivator, perceptions of specific invitations to involvement from the student (e.g., requests to help with homework), and one grounded in personal psychological beliefs, a partnership-focused role construction for involvement (e.g., agreeing with the statement, "I find it helpful to talk with the teacher").

The strong influence of specific invitations from the student is consistent with developmental theory and research (Baumrind, 1991; Maccoby, 1992) and with prior tests of the model. For example, when Deslandes and Bertrand (2005) compared the predictive power of parents' personal psychological beliefs, specific invitations from teachers, and specific invitations from students, student invitations emerged as the 
most powerful predictor of parents' home-based involvement across three middle school grades, accounting for approximately $25 \%$ of the variance at each grade. It is also consistent with related literature documenting that parents of schoolchildren across ethnic and cultural groups tend to become engaged when their children ask for help, explicitly or behaviorally, while working at home on school-related tasks (Delgado-Gaitan, 1992; Gillanders \& Jimenez, 2004; Green et al., 2007).

The power of a partnership-focused role to predict parents' participation in home-based learning activities suggests that these Latino parents generally held beliefs and manifested behaviors focused on "doing their part," in partnership with the school, to support their children's learning. While Sheldon (2002) reported that role construction contributed to both home- and school-based involvement, other tests of the model have found that role construction has more limited influence on parents' home-based involvement activities (e.g., Anderson \& Minke, 2007). Comparisons between this study and prior tests of the model may be complicated by the fact that we construed role as a categorical variable (consistent with Hoover-Dempsey \& Jones, 1997), whereas others have treated it as a continuous variable (Anderson \& Minke, 2007; Deslandes \& Bertrand, 2005; Green et al., 2007).

\section{Predicting School-Based Involvement}

Significant predictors of parents' school-based involvement (e.g., visiting the school during the school day, attending evening meetings or events, attending parent-teacher conferences held during the work day and evening) included the contextual motivator of specific invitations from the teacher (e.g., being asked by the teacher to help out at school), as well as a perceived life-context variable, time and energy for involvement.

The importance of specific invitations from teachers aligns with previous research underscoring the value of teacher outreach in motivating parents' school-based support for their children's education (Epstein, 1986; Hoover-Dempsey et al., 1995, 2005; Simon, 2004) and with other tests of the model constructs (Anderson \& Minke, 2007; Deslandes \& Bertrand, 2005; Green et al., 2007).

The predictive power of parents' time and energy for involvement is consistent with evidence that many families' participation in school-based events, especially low-income families, is often dependent on their ability to conform their schedules and resources to school-imposed constraints (Garcia Coll et al., 2002; HooverDempsey et al., 1995; Pena, 2000; Weiss et al., 2003). Parents' skills and knowledge was not a significant predictor, a finding consistent with other examinations of the model. For example, Green et al. (2007) found that time and energy predicted both home-based and school-based involvement across the elementary and middle school years, yet skills and knowledge did not predict either outcome.

\section{Other Results}

Contrary to our expectations, several variables did not contribute to the regression models. For instance, general invitations to involvement from the school did not predict either form of involvement. Given this variable's positive correlation with both forms of involvement and its negative beta weight in the regression analyses, it is possible that other variables (e.g., the more direct and relationally grounded vari- 
ables of direct invitations from students and from teachers) suppressed its predictive power. Similarly, despite its robust empirical and theoretical foundation, selfefficacy for involvement did not predict either form of involvement. Previous research using the model examined here found that self-efficacy explained small but significant portions of the variance in home-based involvement (Anderson \& Minke, 2007; Deslandes \& Bertrand, 2005; Green et al., 2007; Sheldon, 2002). Its failure to emerge as a predictor here may represent a cultural variation for this Latino sample, or it may represent the need for a more comprehensive or culturally grounded measure of self-efficacy.

\section{Limitations}

Results must be interpreted within several limitations. First, the data were gathered within the context of a multiyear study designed to create measures for all constructs included in the full model (i.e., Levels 1-5) and to test the model's functioning at varied levels and overall. One consequence of these broader purposes was that the measures for each level_-including the ones used here, which focus only on the lower levels of the model- had to be shortened due to concerns that an overly long survey instrument would deter parents' participation. The small number of items per scale may have contributed to some of the relatively low scale reliabilities reported here.

Second, structural analyses of the scales led to the elimination of items from several scales. This affected our ability to test whether two contextual motivations for involvement predicted both forms of involvement. Specifically, given factor loadings, we were unable to test whether specific invitations from students predict school-based involvement and whether specific invitations from teachers predict home-based involvement. These aspects of the model remain untested.

Third, the use of self-report surveys, the accompanying mono-method approach, and the absence of more qualitative measures that might have been implemented with a subsample of research participants limit what can be inferred and known about participants' motivations for involvement. Further, our reliance on volunteer participants and a low response rate are representative of a central methodological challenge to studies of the parent-involvement process; uninvolved parents are difficult to study (Carlson, 1993). We do not know about Latino parents who chose not to, for whatever reasons, participate in the research and how similar or different they might be compared to the sample represented here. Thus our study requires the assumption that results pertain to parents who were somewhat involved in their children's education at least to the extent that they were willing and able to respond to written surveys and return them to the school. They may not be representative of the population of Latino parents whose children attended participating schools.

\section{Implications for Future Research and School Practice}

Findings from this exploratory study offer several suggestions for continued inquiry into Latino parents' motivations for involvement and how schools may further engage their involvement. The findings presented here are preliminary and warrant replication but also offer suggestions for additional research on parental involvement across varied school populations and Latino families' involvement in particular. 
First, future research might use the model examined here to enhance school, teacher, and community knowledge of parents' motivations for and practices of involvement across varied families served by the school, Latino parents, and other groups as pertinent to varied school and community populations. For example, a study might use levels of the theoretical model examined here (Level 1: What motivates parents' involvement? Level 1.5: What forms of involvement do parents choose?) to examine more specifically what motivating variables appear to be particularly important to a school's families and how the school's families, within and across major groups in the school, are responding to the school practices intended to motivate involvement.

Several highly informative studies have employed more qualitative methods to discern effective ways of understanding and supporting parental involvement in many Latino families (e.g., Chrispeels \& Rivero, 2001; De Gaetano, 2007; DelgadoGaitan, 1992; Gonzalez et al., 2001; Moll et al., 1992; Reese et al., 1995; Trevino, 2004). Future investigations might use initial survey findings, such as those offered in this study or in those produced in new work focused on similar goals, in systematic discussion with groups of parents-Latino or other groups- to discern families' experiences with the school, their understanding of the roles they should play supporting their children's learning, and their ideas about what skills, information, and consideration they might need to participate even more effectively in their children's school success.

Second, and more broadly, with the focus of replication and new discovery, future tests of the model might examine various paths of influence among the predictor constructs for many Latino parents. For example, do contextual motivators of involvement, such as teacher and student invitations, mediate the relationship between participating parents' personal psychological beliefs and the extent and types of involvement they choose? How do elements of parents' perceived life context (particularly time and energy) moderate the relationship between their personal psychological beliefs and their involvement behaviors? Do parents have to experience a certain level of skills and knowledge to be able to enact their involvement-related beliefs?

Third, given the predictive power of specific invitations from teachers and students, future work might also examine the impact of varied types of home-school communication on Latino parents' motivations for involvement as well as forms and levels of involvement. For example, how frequently do parents receive, read, and comprehend teacher communications (in English and in Spanish)? What connections do parents perceive between those communications from school and teacher and their decisions about becoming involved, as well as the kinds of involvement they choose? Perhaps particularly important given findings about these Latino parents' strong endorsement of a partnership-focused role construction, future studies may well examine more deeply the contributions of many Latino parents' cultures (the culture of family origin and the culture developed and enacted within the family's U.S. community) to understandings of their own role in their children's learning and their preferences for school support and understanding of their roles. Considerable work has suggested the role and value of positive, mutually respectful, and trusting family-school relationships to parents' involvement decisions, choices, and effectiveness. Exploring more fully how such relationships might be further developed, and the implications of varied levels of family-school trust for parents' involve- 
ment motivations, would add further richness to current knowledge of many Latino (and other) families' understanding of and actions related to the range of parental supports that families may offer their children's school learning.

Because findings in this study and others (e.g., Anderson \& Minke, 2007; Christenson, 2004; Deslandes \& Bertrand, 2005; Epstein \& Van Voorhis, 2001; Green et al., 2007; Moll et al., 1992) have shown that parents' participation in their children's education can be influenced in important ways by specific invitations from teachers, teachers and schools have a powerful motivational tool for parental involvement within their control. However, using teacher invitations to achieve the goal of increased parent involvement requires a teaching workforce that is well prepared to initiate and maintain effective contact with parents. Unfortunately, as several observers and investigators have suggested (see, e.g., Graue \& Brown, 2003), most teachers receive little training in working effectively with families. Thus a potentially fruitful avenue for practice includes offering preservice and inservice teachers more professional development focused on effective, culturally relevant, and specific principles and practices underlying effective and trust-building interactions between families and schools (e.g., Hiatt-Michael, 2001; Hoover-Dempsey, Walker, Jones, \& Reed, 2002).

Professional development experiences might also increase parent involvement by helping teachers to use instructional approaches that capitalize on the motivating power of student invitations (e.g., Epstein \& Van Voorhis, 2001; Gillanders \& Jimenez, 2004; Moll et al., 1992; Reese, 2002; Reese \& Gallimore, 2000). In the same vein, schools might offer programs designed to address parents' and teachers' beliefs about the importance of parent-teacher-school communications, parents' and teachers' actions in attending and engaging with each other at school events and meetings, and specific, culturally relevant information about how parents can actively support their children's learning within the home and community (e.g., Chrispeels \& Rivero, 2001; De Gaetano, 2007). In sum, this study suggests that Latino parents' active role construction, manifested especially as partnership-focused beliefs and actions related to involvement, along with specific invitations to parents' involvement from the teacher, specific invitations to involvement from students, and families' life-context realities regarding time and energy for involvement are all important factors in engaging and sustaining Latino parents' involvement in their children's schooling.

\section{Notes}

This research was supported by the Institute of Education Sciences (OERI/IES R305To10673-03). The authors thank the families and schools who participated in this project. Thanks also to members of the Peabody Family-School Partnership Lab. Correspondence concerning this article should be addressed to Joan Walker, School of Education, Pace University, Pleasantville, NY 10570; e-mail: jwalker@pace.edu.

1. For a graphic representation of the model go to http://www.vanderbilt.edu/Peabody/familyschool/model.html.

2. Copies of the full measures in English and Spanish are available at http://www.vanderbilt .edu/Peabody/family-school/scaledescriptions.html.

\section{References}

Anderson, K. J., \& Minke, K. M. (2007). Parent involvement in education: Toward an understanding of parents' decision making. Journal of Educational Research, 100, 311-323. 
Balli, S. J., Demo, D. H., \& Wedman, J. F. (1998). Family involvement with children's homework: An intervention in the middle grades. Family Relations, 47, 149-157.

Bandura, A. (1997). Self-efficacy: The exercise of control. New York: W. H. Freeman.

Baumrind, D. (1989). Rearing competent children. In W. Damon (Ed.), Child development today and tomorrow (pp. 349-378). San Francisco: Jossey-Bass.

Baumrind, D. (1991). Parenting styles and adolescent development. In R. M. Lerner, A. C. Peterson, \& J. Brooks-Gunn (Eds.), Encyclopedia of adolescence (Vol. 2, pp. 746-758). New York: Garland.

Biddle, B. J. (1986). Recent developments in role theory. Annual Review of Sociology, 12, 67-92.

Bohon, S. A., Macpherson, H., \& Atiles, J. H. (2005). Educational barriers for New Latinos in Georgia. Journal of Latinos and Education, 4, 43-58.

Carlson, C. (1993). The family-school link: Methodological issues in studies of family processes related to children's school competence. School Psychology Quarterly, 8, 264-276.

Chrispeels, J. H., \& Rivero, E. (2001). Engaging Latino families for student success: How parent education can reshape parents' sense of place in the education of their children. Peabody Journal of Education, 76, 119-169.

Christenson, S. L. (2004). The family-school partnership: An opportunity to promote the learning competence of all students. School Psychology Review, 33(1), 83-104.

DeBlassie, A. M., \& DeBlassie, R. R. (1996). Education of Hispanic youth: A cultural lag. Adolescence, 31, 205-216.

De Gaetano, Y. (2007). The role of culture in engaging Latino parents' involvement in school. Urban Education, 42(2), 145-162.

Delgado-Gaitan, C. (1992). School matters in the Mexican-American home: Socializing children to education. American Education Research Journal, 29, 495-513.

Delgado-Gaitan, C. (1994). Socializing young children in Mexican-American families: An intergenerational perspective. In P. M. Greenfield \& R. R. Cocking (Eds.), Cross-cultural roots of minority child development (pp. 55-86). Hillsdale, NJ: Erlbaum.

Delgado-Gaitan, C. (2004). Involving Latino families in schools: Raising student achievement through home-school partnerships. Thousand Oaks, CA: Corwin.

Deslandes, R., \& Bertrand, R. (2005). Motivation of parent involvement in secondary-level schooling. Journal of Educational Research, 98(3), 164-175.

Drummond, K. V., \& Stipek, D. (2004). Low-income parents' beliefs about their role in children's academic learning. Elementary School Journal, 104(3), 197-213.

Eccles, J. S., \& Harold, R. D. (1996). Family involvement during the early adolescent years. In A. Booth \& J. F. Dunn (Eds.), Family-school links: How do they affect education outcomes? (pp. 35-44). Mahwah, NJ: Erlbaum.

Epstein, J. L. (1986). Parents' reactions to teacher practices of parent involvement. Elementary School Journal, 86, 277-294.

Epstein, J. L., \& Van Voorhis, F. L. (2001). More than minutes: Teachers' roles in designing homework. Educational Psychologist, 36, 181-193.

Fan, X., \& Chen, M. (2001). Parental involvement and students' academic achievement: A metaanalysis. Educational Psychology Review, 13, 1-22.

Garcia Coll, C. T., Akiba, D., Palacios, N., Bailey, B., Silver, R., DiMartino, L., . . Bailey, B. (2002). Parental involvement in children's education: Lessons from three immigrant groups. Parenting: Science and Practice, 2, 303-324.

Gillanders, C., \& Jimenez, R. T. (2004). Reaching for success: A close-up of Mexican immigrant parents in the U.S.A. who foster literacy success for their kindergarten children. Journal of Early Childhood Literacy, 4(3), 243-269.

Goldenberg, C., Gallimore, R., Reese, L., \& Garnier, H. (2002). Cause or effect? A longitudinal study of immigrant Latino parents' aspirations and expectations, and their children's school performance. American Educational Research Journal, 38(5), 547-582.

Gonzalez, N., Andrade, R., Civil, M., \& Moll, L. (2001). Bridging funds of distributed knowledge: Creating zones of practice in mathematics. Journal of Education for Students Placed at Risk, 6(1/2), 115-132.

Graue, E., \& Brown, C. P. (2003). Preservice teachers' notions of families and schooling. Teaching and Teacher Education, 19, 719-735. 
Green, C. L., Walker, J. M. T., Hoover-Dempsey, K. V., \& Sandler, H. M. (2007). Parents' motivations for involvement in children's education: An empirical test of a theoretical model of parental involvement. Journal of Educational Psychology, 99, 532-544.

Griffith, J. (2001). Principal leadership of parent involvement. Journal of Educational Administration, 39(2), 162-186.

Grolnick, W. S., Benjet, C., Kurowski, C. O., \& Apostoleris, N. H. (1997). Predictors of parental involvement in children's schooling. Journal of Educational Psychology, 89(3), 538-548.

Grolnick, W. S., Kurowski, C. O., Dunlap, K. G., \& Hevey, C. (2000). Parental resources and the transition to junior high. Journal of Research on Adolescence, 10(4), 465-488.

Grolnick, W. S., Price, C. E., Beiswenger, K. L., \& Sauck, C. C. (2007). Evaluative pressure in mothers: Effects of situation, maternal, and child characteristics on autonomy supportive versus controlling behavior. Developmental Psychology, 43, 991-1002.

Hiatt-Michael, D. (Ed.). (2001). Promising practices for family involvement in school. Greenwich, CT: Information Age.

Hill, N. E., Castellino, D. R., Lansford, J. E., Nowlin, P., Dodge, K. A., Bates, J. E., \& Pettit, G. (2004). Parent academic involvement as related to school behavior, achievement, and aspirations: Demographic variations across adolescence. Child Development, 75(5), 1491-1509.

Hoover-Dempsey, K. V., Bassler, O. C., \& Brissie, J. S. (1992). Explorations in parent-school relations. Journal of Educational Research, 85, 287-294.

Hoover-Dempsey, K. V., Bassler, O. C., \& Burow, R. (1995). Parents' reported involvement in students' homework: Parameters of reported strategy and practice. Elementary School Journal, 95, 435-450.

Hoover-Dempsey, K. V., Ice, C. L., \& Whitaker, M. C. (2009). "We're way past reading together": Why and how does parental involvement during adolescence make sense? In N. Hill \& R. Chao (Eds.), Family-school relationships in adolescence: Linking interdisciplinary research (pp. 19-36). New York: Teachers College Press.

Hoover-Dempsey, K. V., \& Jones, K. P. (1997, March). Parental role construction and parental involvement in children's education. Paper presented at the annual meeting of the American Educational Research Association, Chicago.

Hoover-Dempsey, K. V., \& Sandler, H. M. (1995). Parental involvement in children's education: Why does it make a difference? Teachers College Record, 95, 310-331.

Hoover-Dempsey, K. V., \& Sandler, H. M. (1997). Why do parents become involved in their children's education? Review of Educational Research, 67, 3-42.

Hoover-Dempsey, K. V., \& Sandler, H. M. (2005). Final performance report for OERI grant \# R305T010673: The social context of parental involvement: A path to enhanced achievement. Presented to Project Monitor, Institute of Education Sciences, U.S. Department of Education, March 22.

Hoover-Dempsey, K. V., Walker, J. M. T., Jones, K. P., \& Reed, R. P. (2002). Teachers Involving Parents (TIP): Results of an in-service teacher education program for enhancing parental involvement. Teaching and Teacher Education, 18, 843-867.

Hoover-Dempsey, K. V., Walker, J. M. T., Sandler, H. M., Whetsel, D., Green, C. L., Wilkins, A. S., \& Closson, K. E. (2005). Why do parents become involved? Research findings and implications. Elementary School Journal, 106, 105-130.

Jackson, K., \& Remillard, J. T. (2005). Rethinking parent involvement: African American mothers construct their roles in the mathematics education of their children. School Community Journal, $15,51-73$.

Jeynes, W. H. (2003). A meta-analysis: The effects of parental involvement on minority children's academic achievement. Education and Urban Society, 35, 202-218.

Jeynes, W. H. (2007). The relationship between parental involvement and urban secondary school student academic achievement: A meta-analysis. Urban Education, 42, 82-110.

Kohl, G. W., Lengua, L. J., \& McMahon, R. J. (2002). Parent involvement in school: Conceptualizing multiple dimensions and their relations with family and demographic risk factors. Journal of School Psychology, 38(6), 501-523.

Llagas, C., \& Snyder, T. D. (2003). Status and trends in the education of Hispanics (NCES 2003-008). U.S. Department of Education, NCES. Washington, DC: U.S. Government Printing Office. 
Lopez, L. C., Sanchez, V. V., \& Hamilton, M. (2000). Immigrant and native-born Mexican-American parents' involvement a public school: A preliminary study. Psychological Reports, 86, 521-525.

Maccoby, E. E. (1992). The role of parents in the socialization of children. Developmental Psychology, 28(6), 1006-1017.

Marschall, M. (2006). Parent involvement and educational outcomes for Latino students. Review of Policy Research, 23(5), 1053-1076.

Moll, L., Amanti, C., Neff, D., \& Gonzalez, N. (1992). Funds of knowledge for teaching: Using a qualitative approach to connect homes and classrooms. Theory into Practice, 31, 132-141.

Okagaki, L., Frensch, P. A., \& Gordon, E. W. (1995). Encouraging school achievement in Mexican American children. Hispanic Journal of Behavioral Sciences, 17(2), 160-179.

Patrikakou, E. N., \& Weissberg, R. P. (2000). Parents' perceptions of teacher outreach and parent involvement in children's education. Journal of Prevention and Intervention in the Community, 20(1/2), 103-119.

Pena, D. C. (2000). Parent involvement: Influencing factors and implications. Journal of Educational Research, 94(1), 42-45.

Reese, L. (2002). Parental strategies in contrasting cultural settings: Families in Mexico and "El Norte." Anthropology and Education Quarterly, 33, 30-59.

Reese, L., Balzano, S., Gallimore, R., \& Goldenberg, C. (1995). The concept of educación: Latino family values and American schooling. International Journal of Educational Research, 23, 57-81.

Reese, L. J., \& Gallimore, R. (2000). Immigrant Latinos' cultural model of literacy development: An alternative perspective on home-school discontinuities. American Journal of Education, 108(2), 103-134.

Rodriguez, J. L. (2002). Family environment and achievement among three generations of Mexican-American high school students. Applied Developmental Science, 6, 88-94.

Rodriguez, J. L. (2009). Considering the context of culture: Perspectives in the schooling of Latino adolescents from the classroom, home, and beyond. In N. H. Hill \& R. K. Chao (Eds.), Families, schools and the adolescent: Connecting research, policy and practice (pp. 37-52). New York: Teachers College Press.

Scribner, J. D., Young, M. D., \& Pedroza, A. (1999). Building collaborative relationships with parents. In P. Reyes, J. D. Scribner, \& A. P. Scribner (Eds.), Lessons from high performing Hispanic schools: Creating learning communities. Williston, VT: Teachers College Press.

Sheldon, S. B. (2002). Parents' social networks and beliefs as predictors of parent involvement. Elementary School Journal, 102(4), 301-316.

Simon, B. S. (2004). High school outreach and family involvement. Social Psychology of Education, 7, 185-209.

Trevino, R. E. (2004). Against all odds: Lessons from parents of migrant high-achievers. In C. Salinas \& M. E. Fránquiz (Eds.), Scholars in the field: The challenges of migrant education (pp. 147-161). Charleston, WV: AEL.

Trusty, J., Plata, M., \& Salazar, C. F. (2003). Modeling Mexican Americans' educational expectations: Longitudinal effects of variables across adolescence. Journal of Adolescent Research, 18(2), $131-153$.

Valdés, G. (1996). Con respeto: Bridging the distances between culturally diverse families and schools. New York: Teachers College Press.

Valencia, R. R., \& Black, M. S. (2002). Mexican Americans don't value education! On the basis of the myth, mythmaking, and debunking. Journal of Latinos and Education, 1, 81-103.

Walker, J. M. T., Wilkins, A. S., Dallaire, J. P., Sandler, H. M., \& Hoover-Dempsey, K. V. (2005). Parental involvement: Model revision through scale development. Elementary School Journal, 106, 85-104.

Waxman, H. C., Huang, S. L., \& Padrón, Y. N. (1997). Motivation and learning environment differences between resilient and non-resilient Latino middle school students. Hispanic Journal of Behavioral Sciences, 19, 137-155.

Weiss, H. B., Mayer, E., Kreider, H., Vaughan, M., Dearing, E., Hencke, R., \& Pinto, K. (2003). Making it work: Low-income working mothers' involvement in their children's education. American Educational Research Journal, 40, 879-901.

$\mathrm{Xu}, \mathrm{J}$. , \& Corno, L. (2003). Family help and homework management reported by middle school students. Elementary School Journal, 103(5), 503-536. 